\title{
The external fixation can be a good alternative to plate-screw treatment in the surgical treatment of bilateral distal radius fractures: A retrospective cohort study
}

\author{
Mirza Zafer Dağtaş, MD (D), Ömer Kays Ünal, MD (D) \\ Department of Orthopedics and Traumatology, Maltepe University, Medical School, Istanbul, Turkey
}

Distal radius fractures (DRFs) are commonly encountered in trauma practice with most cases being elderly individuals. Seventy percent of all DRFs occur as a result of low-energy traumas, usually during the winter month. ${ }^{[1]}$ In younger patients, the etiology is often high-energy trauma, whereas older patients can suffer DRFs after a simple fall on an open hand-due to the high prevalence of osteoporosis. ${ }^{[2]}$ Patients can be treated conservatively or through surgery, depending on the type of fracture. For simple fractures, conservative treatment can be sufficient, while surgical treatment may be inevitable for complex fractures. ${ }^{[3]}$ Surgical treatment options include closed pinning, open reduction and internal fixation (ORIF), external fixator (EF) application, and various combinations of these techniques. ${ }^{[4]}$ Although the most optimal surgical approach to DRF treatment remains as a topic of controversy, ${ }^{[4]}$ when the fracture

Received: April 08, 2021

Accepted: May 17, 2021

Published online: June 11, 2021

Correspondence: Mirza Zafer Dağtaș, MD. Maltepe Üniversitesi Tıp Fakültesi Ortopedi ve Travmatoloji Anabilim Dalı,

34844 Maltepe, İstanbul, Türkiye.

E-mail: zaferdagtas@hotmail.com

Doi: $10.52312 /$ jdrs.2021.151

Citation: Dağtas $M Z$, Ünal ÖK. The external fixation can be a good alternative to plate-screw treatment in the surgical treatment of bilateral distal radius fractures: A retrospective cohort study. Jt Dis Relat Surg 2021;32(2):406-413.

(C2021 All right reserved by the Turkish Joint Diseases Foundation

This is an open access article under the terms of the Creative Commons Attribution-NonCommercial License, which permits use, distribution and reproduction in any medium, provided the original work is properly cited and is not used for commercial purposes (http://creativecommons.org/licenses/by-nc/4.0/).

\section{ABSTRACT}

Objectives: We aimed to compare the outcomes of two surgical treatment options, external fixator (EF) or open reduction and internal fixation (ORIF), in patients with bilateral distal radius fractures (DRFs).

Patients and methods: Twenty-one patients (11 males 10 females; mean age: $40.0 \pm 16.0$ years; range, 20 to 67 years) who underwent ORIF $(n=10)$ or $E F(n=11)$ due to bilateral DRF at between January 2011 and December 2019 were retrospectively analyzed. The Quick Disability of the Arm, Shoulder and Hand (Q-DASH) was used to calculate functional and symptomatic evaluation. The MAYO wrist scores were used to evaluate pain, functional status, ROM, and grip strength and the Michigan Hand Outcomes Questionnaire (MHOQ) was used to measure hand performance in daily life.

Results: The operation time was statistically significantly longer in the ORIF group, compared to the EF group ( $\mathrm{p}<0.001)$. Radial shortening was statistically significantly greater in the EF group, compared to the ORIF group $(\mathrm{p}<0.001)$. While the Q-DASH score was lower in the EF group on Day 15 and at one and two months $(\mathrm{p}<0.001$, for each), it was similar between the groups at one year $(p=0.507)$. The MAYO wrist score was higher in the EF group on Day 15 and at one and two months and one year $(\mathrm{p}<0.05$, for each). While the MHOQ score was higher in the EF group on Day 15 and at one and two months $(\mathrm{p}<0.001$, for each), it was similar between the groups at one year $(\mathrm{p}=0.557)$.

Conclusion: In bilateral DRF cases, hand functions in the first two months after treatment were better in the EF group, compared to the ORIF group. This functional difference between the two groups gradually decreased in the first year and reached similar levels. Our results demonstrate that EF can be a good alternative in the surgical treatment of bilateral DRFs owing to its acceptable results, particularly in the short-term.

Keywords: Bilateral distal radius fracture, external fixators, open reduction and internal fixation.

is unilateral, treatment modality and type of implant to be used can be selected based on the literature and according to the fracture type and surgical expertise. However, since bilateral DRF is seen very rarely, the 
approach to surgical treatment of bilateral cases is largely unclear. ${ }^{[5]}$

Temporary splint is usually applied after ORIF. For bilateral DRFs, this can be challenging since daily activities, social life, and self-care of the patient may be adversely affected. ${ }^{[5]}$ On the other hand, after EF, a splint is not necessary, and the patient can use both hands more freely than an ORIF recipient. This situation may positively affect patients' quality of life and surgery-related satisfaction. ${ }^{[6]}$

In the present study, we hypothesized that, in the treatment of bilateral DRFs, the utilization of EF would result in better results compared to ORIF. We, therefore, aimed to compare the results of EF and ORIF treatments in patients with bilateral DRFs.

\section{PATIENTS AND METHODS}

This retrospective cohort study was conducted at Maltepe University, Medical School, Department of
Orthopedics and Traumatology between January $1^{\text {st }}$, 2011 and December 31 ${ }^{\text {st }}$, 2019. A total of 48 patients underwent surgery for bilateral DRFs during the study period. Inclusion criteria were as follows: age $\geq 18$ years, having an isolated DRF, having a previous surgery via the EF or ORIF procedures (volar plate), and having attended to regular outpatient follow-up for at least one year. Finally, 21 patients (11 males 10 females; mean age: $40.0 \pm 16.0$ years; range, 20 to 67 years) who met the inclusion criteria were included. The EF was applied to seven cases who could not be given long-term anesthesia for various reasons (due to shorter operation time), two cases with incision site dermabrasion, and two cases who were living alone and could not perform self-care on their own. The ORIF treatment was performed to the remaining cases. The patients were divided into two groups according to the surgical approach as those undergoing EF treatment $(n=11)$ and those undergoing ORIF treatment $(n=10)$. A written informed consent was obtained from each patient. The study protocol
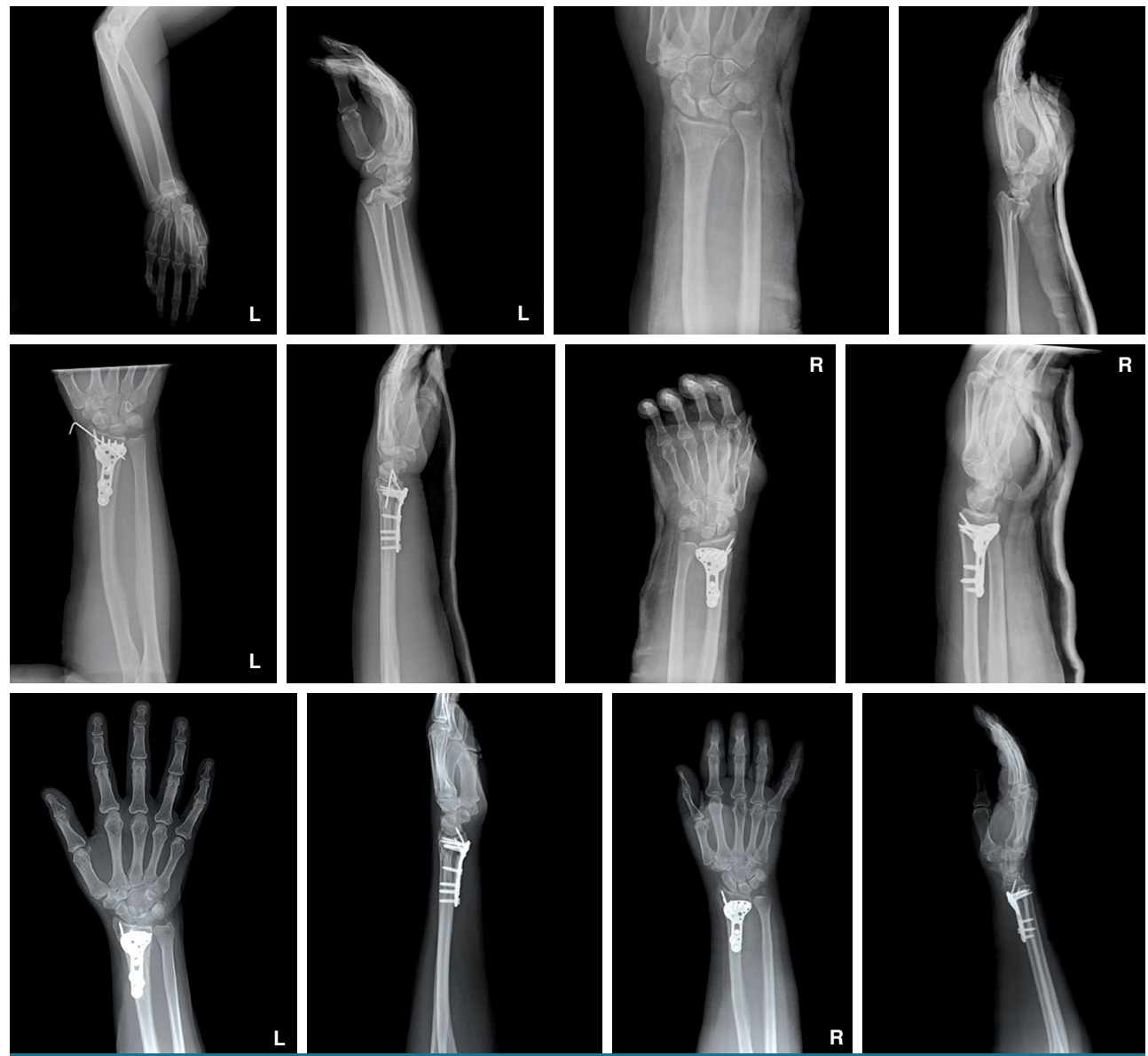

FIGURE 1. Pre- and postoperative graphs of bilateral distal radial fracture in ORIF group. ORIF: Open reduction internal fixation.
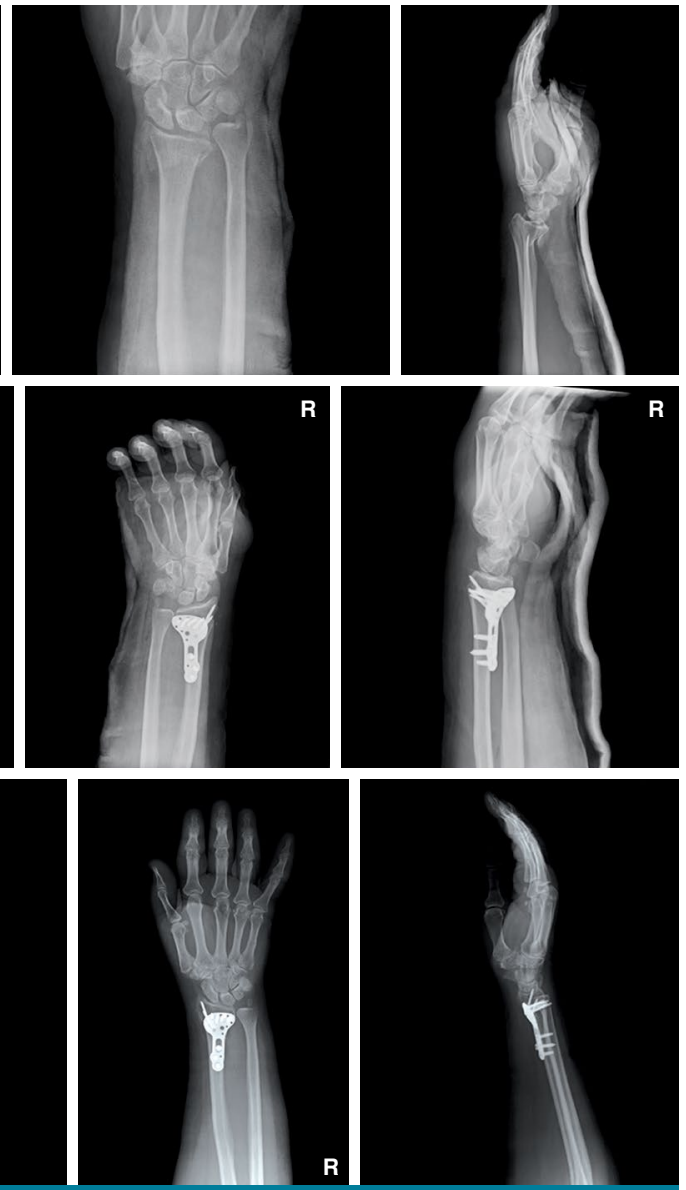

1


was approved by the Maltepe University, Medical School Ethics Committee (2020/900/64). The study was conducted in accordance with the principles of the Declaration of Helsinki.

\section{Surgical technique}

All operations were carried out under regional or general anesthesia with patients in the supine position and $1.5 \mathrm{~g}$ of cefuroxime axetil was administered for prophylaxis. After preparation using the aseptic technique, closed reduction was performed under fluoroscopy, and percutaneous Schanz nails were placed distally to the second and third metacarpals and proximally to the radius shaft. After placing the pins, external fixators were applied in the EF group.

For the ORIF group, all operations were carried out similarly, with the patient in supine position under regional or general anesthesia and $1.5 \mathrm{~g}$ of cefuroxime axetil prophylaxis. After preparation, a longitudinal incision was made slightly radial to the flexor carpi radialis (FCR). The FCR tendon was retracted toward the ulna while protecting the median nerve. Dissection was performed through the floor of the FCR sheath, the radial artery was retracted laterally and the pronator quadratus (PQ) was exposed. The PQ was released in the radial to ulnar direction by sharp incision over the watershed line and proximally on the lateral edge of the radius, and the PQ was elevated to expose the volar surface of the radius. Fracture reduction was performed, and fixation was applied with volar plate and screws. In both groups, all operations were performed simultaneously.

Demographic features, fracture type according to the $\mathrm{AO}$ classification system, range of motion (ROM) findings, and postoperative complications were obtained from medical records. The classification of DRFs were made according to the AO Foundation/ Orthopedic Trauma Association (OTA) fracture classification. ${ }^{[7]}$ All DRFs were evaluated according to the Mann's radiological evaluation criteria. ${ }^{[8]}$ Radial shortness, inclination, and volar tilt were measured in all patients at the latest follow-up ( $1^{\text {st }}$ year) on X-ray images (Figures 1 and 2).
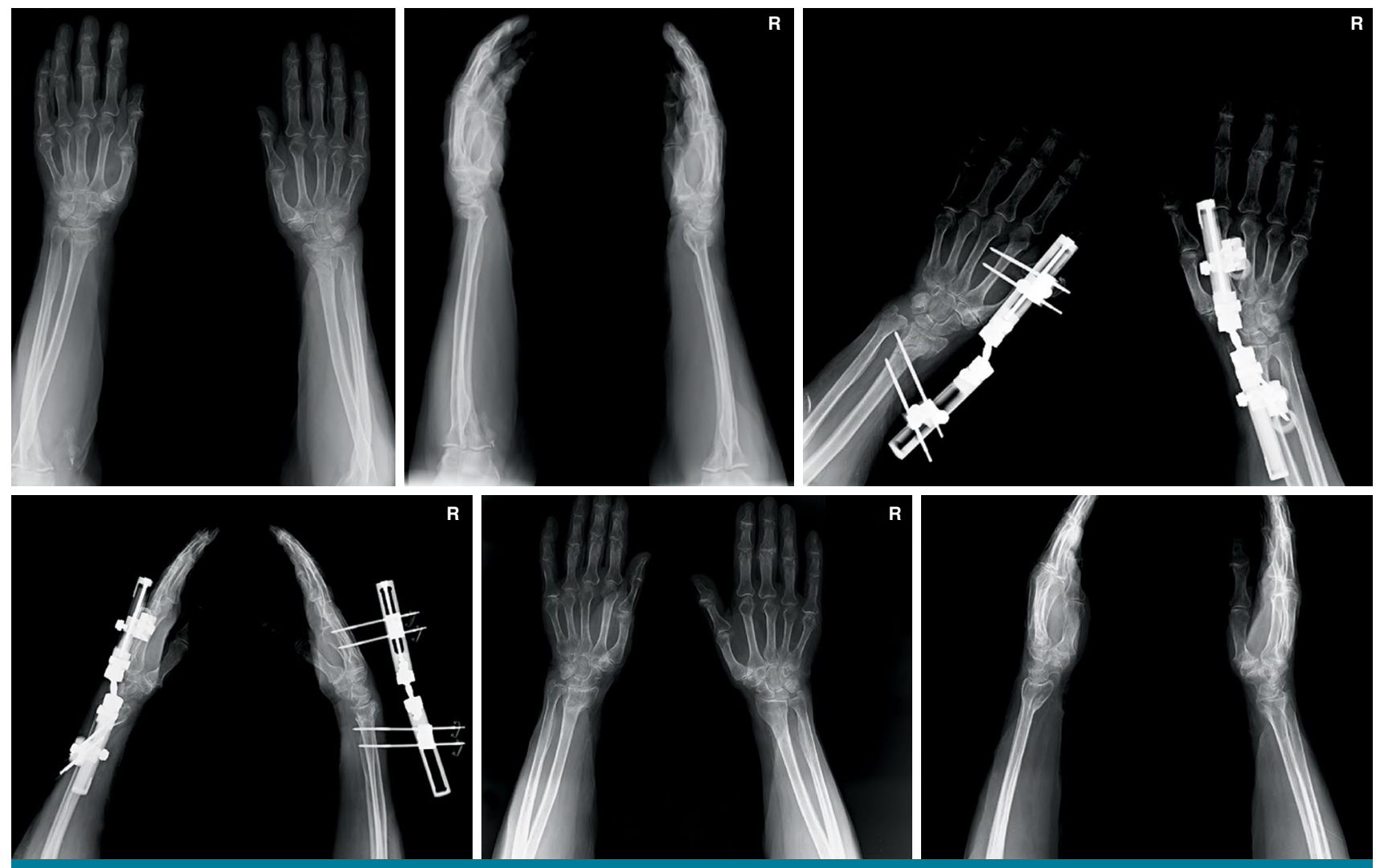

FIGURE 2. Pre- and postoperative graphs of bilateral distal radial fracture in EF group.

EF: External fixator. 


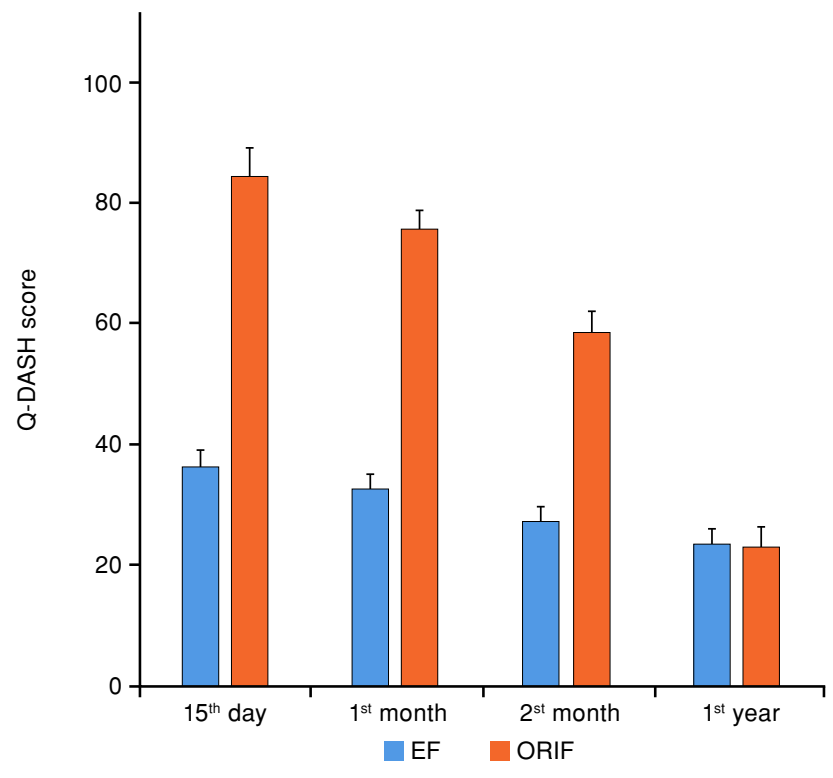

FIGURE 3. Q-DASH scores of patient groups.

EF: External fixator; ORIF: Open reduction and internal fixation; Q-DASH: Quick disability of the arm, shoulder and hand.

\section{Assessment tools}

The Quick Disability of the Arm, Shoulder and Hand (Q-DASH) score, the MAYO wrist scores, and Michigan Hand Outcomes Questionnaire (MHOQ) scores were used. Although the MAYO scores and the Q-DASH scores were similar to each other, the MAYO scores of the patients were calculated simultaneously to prove the consistency of the Q-DASH results of our study. The Q-DASH, MAYO, scores and MHOQ scores were recorded at three time points (Day 15, Day 30, Day 60 and at the last follow-up visit at 12 months postoperatively.

The Q-DASH is used for functional and symptomatic evaluation. The scores of the patients are calculated based on responses with a maximum value of 100. Higher scores indicate worse results..$^{[9]}$

The MAYO wrist score is used to evaluate pain, functional status, ROM, and grip strength. Each of these four dimensions receives a score out of 25. A higher score indicates a better result. ${ }^{[10]}$

The MHOQ is a self-report questionnaire utilized as a standard instrument to measure hand performance in daily life. It consists of six subscales: (i) general hand function, (ii) daily activities, (iii) pain, (iv) work performance, (v) aesthetics, and (vi) individual satisfaction with hand function. In each subscale, patients' response to items are evaluated through a five-point Likerttype scoring system. ${ }^{[11]}$

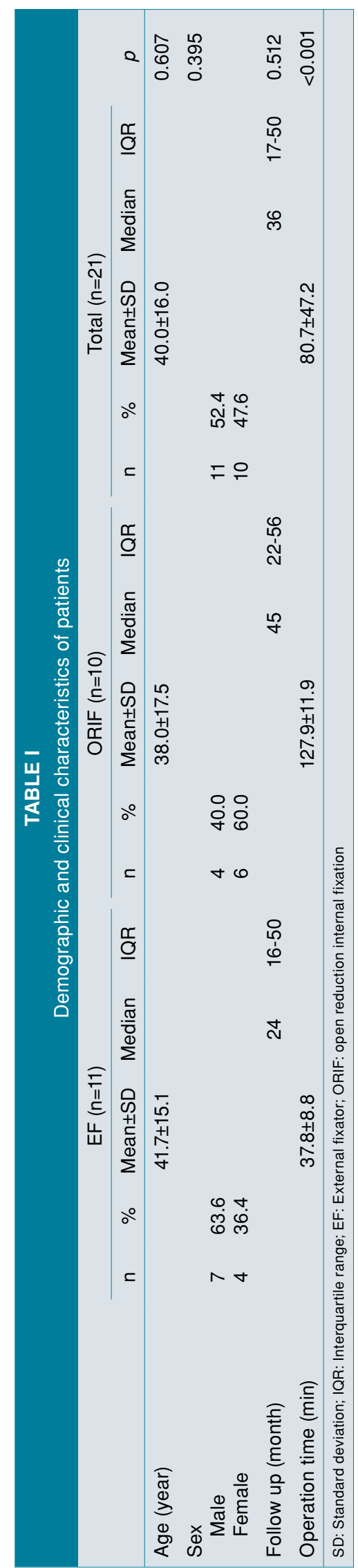




\begin{tabular}{|c|c|c|c|c|c|}
\hline Fracture cla & & omplic & rat & & \\
\hline & & & & & \\
\hline & & 22) & & $=20)$ & \\
\hline AO classification & $\mathrm{n}$ & $\%$ & $\mathrm{n}$ & $\%$ & $p$ \\
\hline 2R3B2.1 & 0 & 0.0 & 1 & 5.0 & 0.711 \\
\hline 2R3B2.2 & 8 & 36.4 & 8 & 40.0 & \\
\hline 2R3B2.3 & 2 & 9.1 & 1 & 5.0 & \\
\hline 2R3B3.1 & 3 & 13.6 & 3 & 15.0 & \\
\hline 2R3B3.3 & 3 & 13.6 & 1 & 5.0 & \\
\hline 2R3C1.1 & 3 & 13.6 & 5 & 25.0 & \\
\hline 2R3C1.2 & 3 & 13.6 & 1 & 5.0 & \\
\hline Complications & 7 & 31.8 & 5 & 25.0 & 0.625 \\
\hline Infection & 4 & 18.2 & 1 & 5.0 & 0.346 \\
\hline Tendonitis & 1 & 4.5 & 2 & 10.0 & 0.598 \\
\hline Wrist stiffness & 1 & 4.5 & 1 & 5.0 & 1.0 \\
\hline Chronic regional pain syndrome & 1 & 4.5 & 0 & 0.0 & 1.0 \\
\hline Carpal tunnel syndrome & 0 & 0.0 & 1 & 5.0 & 0.476 \\
\hline
\end{tabular}

\begin{tabular}{|c|c|c|c|c|c|c|c|}
\hline \multicolumn{8}{|c|}{$\begin{array}{l}\text { TABLE III } \\
\text { nt outcomes of patient groups }\end{array}$} \\
\hline & \multicolumn{6}{|c|}{ Approach } & \multirow[b]{3}{*}{$p$} \\
\hline & \multicolumn{3}{|c|}{$E F(n=22)$} & \multicolumn{3}{|c|}{ ORIF $(n=20)$} & \\
\hline & Mean $\pm S D$ & Median & IQR & Mean $\pm S D$ & Median & IQR & \\
\hline \multicolumn{8}{|l|}{ Wrist range of motion $\left(^{\circ}\right)$} \\
\hline Extension & & 54.0 & $45.0-57.0$ & & 54.0 & $47.0-57.0$ & 0.426 \\
\hline Flexion & $49.8 \pm 7.3$ & & & $53.3 \pm 7.9$ & & & 0.148 \\
\hline Radial deviation & & 17.5 & $16.0-23.0$ & & 22.5 & $17.5-24.0$ & 0.108 \\
\hline Ulnar deviation & & 22.0 & $20.0-24.0$ & & 22.5 & $21.5-26.0$ & 0.368 \\
\hline \multicolumn{8}{|l|}{ Forearm range of motion $\left({ }^{\circ}\right)$} \\
\hline Pronation & $60.1 \pm 7.8$ & & & $62.3 \pm 6.7$ & & & 0.361 \\
\hline Supination & & 59.0 & $55.0-67.0$ & & 61.5 & $56.0-66.5$ & 0.527 \\
\hline \multicolumn{8}{|l|}{ Radiographic measurements } \\
\hline Radial shortening (mm) & & 2.3 & $2.0-3.0$ & & 1.3 & $1.0-1.9$ & $<0.001$ \\
\hline Radial inclination $\left({ }^{\circ}\right)$ & $18.2 \pm 3.2$ & & & $19.0 \pm 3.6$ & & & 0.439 \\
\hline Volar tilt (mm) & & 6.3 & $6.0-7.0$ & & 6.3 & $5.5-7.0$ & 0.990 \\
\hline \multicolumn{8}{|l|}{ Q-DASH score } \\
\hline $15^{\text {th }}$ day & $36.2 \pm 2.9$ & & & $84.4 \pm 4.8$ & & & $<0.001$ \\
\hline $1^{\text {st }}$ month & & 34.0 & $32.0-34.0$ & & 76.0 & $76.0-78.0$ & $<0.001$ \\
\hline $2^{\text {nd }}$ month & $26.9 \pm 2.9$ & & & $58.4 \pm 3.6$ & & & $<0.001$ \\
\hline $1^{\text {st }}$ year & $23.6 \pm 2.3$ & & & $22.8 \pm 3.3$ & & & 0.507 \\
\hline \multicolumn{8}{|l|}{ MAYO wrist score } \\
\hline $15^{\text {th }}$ day & $66.4 \pm 2.5$ & & & $28.0 \pm 3.4$ & & & $<0.001$ \\
\hline $1^{\text {st }}$ month & $71.64 \pm 2.0$ & & & $31.0 \pm 3.2$ & & & $<0.001$ \\
\hline $2^{\text {nd }}$ month & & 76.0 & $72.0-78.0$ & & 34.0 & $34.0-38.0$ & $<0.001$ \\
\hline $1^{\text {st }}$ year & $75.3 \pm 3.4$ & & & $71.8 \pm 3.1$ & & & 0.023 \\
\hline \multicolumn{8}{|l|}{ Michigan hand score } \\
\hline $15^{\text {th }}$ day & & 76.0 & $74.0-78.0$ & & 24.0 & $22.0-26.0$ & $<0.001$ \\
\hline $1^{\text {st }}$ month & & 80.0 & $78.0-80.0$ & & 33.0 & $32.0-34.0$ & $<0.001$ \\
\hline $2^{\text {nd }}$ month & $81.6 \pm 2.3$ & & & $44.8 \pm 3.4$ & & & $<0.001$ \\
\hline $1^{\text {st }}$ year & & 84.0 & $84.0-86.0$ & & 86.0 & $82.0-88.0$ & 0.557 \\
\hline
\end{tabular}




\section{Statistical analysis}

Statistical analysis was performed using the IBM SPSS version 21.0 software (IBM Corp., Armonk, NY, USA). For the normality check, the Shapiro-Wilk test was used. Data are presented in mean \pm standard deviation (SD) or median ( $1^{\text {st }} 3^{\text {rd }}$ quartiles) for continuous variables according to normality of distribution, and in number and frequency for categorical variables. Normally distributed variables were analyzed using the independent samples t-test. Non-normally distributed variables were analyzed using the Mann-Whitney $U$ test. Categorical variables were evaluated using the chi-square tests and the Fisher's exact test was used, when necessary. A two-tailed $p$ value of $<0.05$ was considered statistically significant.

\section{RESULTS}

There was no statistically significant difference between the EF and ORIF groups in terms of age, sex, and follow-up duration $(\mathrm{p}=0.607, \mathrm{p}=0.395, \mathrm{p}=0.512$, respectively). However, the operation time was statistically significantly longer in the ORIF group, compared to the EF group $(\mathrm{p}<0.001)$ (Table I).

Complications were observed in $31.8 \%$ of the EF group and $25.0 \%$ of the ORIF group. There was no significant difference between the groups in terms of $\mathrm{AO}$ classification and complication development ( $\mathrm{p}=0.711, \mathrm{p}=0.625$, respectively) (Table II).

There was no significant difference between the groups in terms of ROM of the wrist and forearm joints ( $p>0.05$, for each). In radiological evaluation, radial shortening was statistically significantly greater in the EF group, compared to the ORIF group $(\mathrm{p}<0.001)$. While the Q-DASH score was lower in the EF group on Day 15 and at one and two months $(\mathrm{p}<0.001$, for each), it was similar between the groups at one year $(p=0.507)$. The MAYO wrist score was higher in the EF group on Day 15 and at one and two months and one year ( $\mathrm{p}<0.05$, for each). While the MHOQ score was higher in the EF group on Day 15 and at one and two months ( $p<0.001$, for each), it was similar between the groups at one year $(p=0.557)$ (Table III).

\section{DISCUSSION}

Bilateral DRFs are exceedingly rare compared to unilateral DRFs. ${ }^{[12]}$ While $87 \%$ of unilateral DRFs are treated conservatively, ${ }^{\left[{ }^{[3]}\right.}$ ORIF is the most widely adopted surgical treatment. ${ }^{[13]}$ No specific treatment has been described for bilateral DRFs in the literature. Due to the rarity of bilateral DRFs, comparative studies with different surgical approaches in bilateral DRFs are few. In the present study, in which the results of EF and ORIF approaches were compared in bilateral DRF cases, we found that the EF approach was a feasible treatment alternative for bilateral DRFs, as it was easy to apply with satisfactory results. In addition, the Q-DASH and MHOQ scores were better in the EF group within the first two months, whereas these scores were comparable between the groups at one year. The MAYO wrist score was also improved in the EF group in all time points of follow-up in the first year. Moreover, radial shortening was greater in the EF group.

In previous studies, scoring systems such as the Q-DASH and MAYO have been used in the functional evaluation of wrist surgery. Williksen et al. ${ }^{[14]}$ used both the Q-DASH and the MAYO scores; however, some surgeons used only Q-DASH scores..$^{[4,11-13]}$ In a meta-analysis, Wang et al. ${ }^{[15]}$ reported that higher DASH scores were observed with ORIF, compared to EF. In contrast, one year later, in the meta-analysis of Lee et al., ${ }^{[16]}$ there was no significant difference between the ORIF and EF groups in terms of the Q-DASH scores. Similarly, in a more recent meta-analysis, Gouk et al. ${ }^{[17]}$ showed that there was no statistically significant difference in long-term functional outcomes between DRF cases undergoing ORIF and EF. While Williksen et al. ${ }^{[14]}$ found that Q-DASH scores were similar in ORIF and EF surgeries in their study, they also reported that the MAYO scores of the ORIF procedure were higher. The discrepancy between the studies may have resulted from the inhomogeneity of the characteristics of the cases, the severity of the fracture, and the surgeon's experience. Due to the controversial results in the literature, we used three functional scores in our study. Accordingly, the Q-DASH, MAYO, and MHOQ scores were improved on Day 15, at one and two months of follow-ups in the EF group. In the first year of follow-up, the Q-DASH and MHOQ scores were similar between the groups, while the MAYO wrist score was still better in the EF group. Although functional results were improved in the EF group compared to ORIF in the early postoperative period, this difference may decrease in the mid- to -long-term. The decrease in the difference between the MAYO wrist scores of the groups at one year of follow-up also supports this assumption. With longer followup of the cases, more accurate interpretations can be made in terms of mid- to long-term results. Based on our study results, we can speculate that EF (probably as it is less invasive) has better functional results in the early period.

The ROM is the basic evaluation criterion for postsurgical evaluation and follow-up of DRFs. Gouk et al. ${ }^{[17]}$ reported that, in the long-term follow-up of 
DRF cases, ORIF had better ROM values compared to $\mathrm{EF}$, although it was not statistically significant. Similarly, Schmelzer-Schmied et al. ${ }^{[18]}$ studied 45 patients aged between 50 and 70 years with dorsally displaced distal DRF who were operated with EF or ORIF and reported that ROM was significantly better for ORIF than EF. Huang et al., ${ }^{[19]}$ in their series of 69 patients, found higher ROM values in ORIF compared to EF and they showed an $80^{\circ}$ mid-supination that was statistically better in the ORIF group. In our study, we found that wrist extension, flexion, radial deviation, ulnar deviation, forearm pronation, and forearm supination degrees were not significantly different between the ORIF and EF groups. In contrast to previous studies, the fact that no significant difference was found between the groups in our study may be due to the small sample size, relatively short follow-up, and presence of the bilateral fractures.

Radiological evaluation is an important criterion in evaluating the success of treatment in fractures. A study conducted by Mellstrand Navarro et al., ${ }^{[20]}$ including 140 DRF patients aged between 50 and 74 years who were operated with ORIF or EF, showed that radiographic findings associated with healing were better in the ORIF group compared to the EF group. Egol et al. ${ }^{[2]}$ reported in their 280 -case series that there was no significant difference between ORIF and $\mathrm{EF}$ in terms of radiographic images obtained one year after surgery. Also, in different studies, there was no statistically significant difference in radiological parameters between the ORIF and EF groups, consistent with the previous study. ${ }^{[1,22]}$ In our study, we found that the results of radiological measurements between ORIF and EF were similar to each other at the end of the first year of follow-up, except for radial shortening. Radial shortening was greater in the EF group compared to the ORIF group. Wright et al. ${ }^{[23]}$ suggested that the fixed-angle plate prevented shortening of the radius in the ORIF group, while EF might lead to greater radial shortening due to late setting at the fracture site. We believe that this outcome may have arisen for this reason.

In the literature, different complication rates have been described in DRF surgeries. SchmelzerSchmied et al. ${ }^{[18]}$ definitely reported more frequent complications with the utilization of EF. In the aforementioned study, infection, non-union, reflex dystrophia, and malunion were detected only among patients who underwent EF. On the other hand, carpal tunnel syndrome was seen in only the ORIF group. Huang et al. ${ }^{[19]}$ observed significant differences in the incidence of complications between these two surgeries. A higher incidence of infection was noted in the EF group and, also, the overall complication and infection rates of the EF group were relatively higher. The studies published by Williksen et al. ${ }^{[14]}$ and Mellstrand Navarro et al. ${ }^{[20]}$ reported no significant difference between ORIF and EF in terms of complication rates. In our study, similarly, we could not find any significant difference between ORIFs and EFs in terms of complication frequency. Although the infection rate was four times higher in the EF group than in the ORIF group, all infections in the EF group were identified as pin-tract infections that healed after oral antibiotics. Recent studies comparing EF and ORIF have also reported a large difference in the rate of infection between these two procedures. Esposito et al. ${ }^{[24]}$ reported a pin tract infection rate of 9.8\% in patients treated with $\mathrm{EF}$ versus $2.8 \%$ in the ORIF group. Furthermore, a meta-analysis of 1,520 surgically treated DRFs showed that the infection rate was nearly $11 \%$ in fractures treated with $\mathrm{EF}$, whereas this rate was only $0.8 \%$ in patients treated with internal fixation. ${ }^{[25]}$

Although not examined in our study, it has been shown that conservative treatments have successful results in the treatment of DRF. Although plaster immobilization has the advantage of being non-invasive, union problems overshadow this advantage. ${ }^{[26]}$ In recent meta-analyses, surgical and conservative treatments have different advantages and disadvantages in the treatment of DRF cases and the first option is in favor of conservative treatment, although it varies according to the clinician's decision. ${ }^{[27,28]}$ In future studies, more accurate results can be obtained by comparing the results of conservative treatment and surgical treatment in bilateral DRF cases.

There are some limitations to our study. The first is the low number of patients with bilateral DRFs who were surgically treated; however, bilateral DRFs are rare occurrences and the inclusion criteria employed for our study also reduced the sample size. Second, we could not collect other outcome data due to the retrospective nature of this study. Considering the varying results of different studies, future studies may benefit from recorded a greater number of outcome measures in patients treated for DRFs.

The main strength of the study is that it is the first study in the literature to include patients with bilateral DRF and compare two widely adopted methods of surgical treatment in these patients. This study also suggests that, even if a particular method is considered as the ideal method for the treatment of unilateral radial fractures, the same method may 
not yield such a success in patients with bilateral fractures.

In conclusion, in bilateral DRFs cases, hand functions within the first two months after treatment were better in the EF group compared to the ORIF group. This functional difference between the two groups gradually decreased in the first year and reached similar levels over time. Besides, the frequency of complications was similar between the groups. Based on these findings, EF seems to be a good alternative in the surgical treatment of bilateral DRFs owing to its acceptable results, particularly in the short-term.

\section{Declaration of conflicting interests}

The authors declared no conflicts of interest with respect to the authorship and/or publication of this article.

\section{Funding}

The authors received no financial support for the research and/or authorship of this article.

\section{REFERENCES}

1. Flinkkilä T, Sirniö K, Hippi M, Hartonen S, Ruuhela R, Ohtonen $\mathrm{P}$, et al. Epidemiology and seasonal variation of distal radius fractures in Oulu, Finland. Osteoporos Int 2011;22:2307-12.

2. Kibar B. Combined palmar and dorsal plating of four-part distal radius fractures: Our clinical and radiological results. Jt Dis Relat Surg 2021;32:59-66.

3. Huetteman HE, Shauver MJ, Malay S, Chung TT, Chung KC. Variation in the treatment of distal radius fractures in the United States: 2010 to 2015. Plast Reconstr Surg 2019;143:159-67.

4. Talmaç MA, Görgel MA, Kanar M, Tok O, Özdemir HM. Comparison of three surgical methods in the treatment of intraarticular comminuted distal radius fractures: Volar locking plate, non-bridging external fixator, and bridging external fixator. Eklem Hastalik Cerrahisi 2019;30:224-32.

5. Ehsan A, Stevanovic M. Skeletally mature patients with bilateral distal radius fractures have more associated injuries. Clin Orthop Relat Res 2010;468:238-42.

6. Kumbaraci M, Kucuk L, Karapinar L, Kurt C, Coskunol E. Retrospective comparison of external fixation versus volar locking plate in the treatment of unstable intra-articular distal radius fractures. Eur J Orthop Surg Traumatol 2014;24:173-8.

7. Meinberg EG, Agel J, Roberts CS, Karam MD, Kellam JF. Fracture and dislocation classification compendium-2018. J Orthop Trauma 2018;32 Suppl 1:S1-S170.

8. Mann FA, Raissdana SS, Wilson AJ, Gilula LA. The influence of age and gender on radial height. J Hand Surg Am 1993;18:711-3.

9. Koldas Dogan S, Ay S, Evcik D, Baser O. Adaptation of Turkish version of the questionnaire quick disability of the arm, shoulder, and hand (Quick DASH) in patients with carpal tunnel syndrome. Clin Rheumatol 2011;30:185-91.

10. Cooney WP, Bussey R, Dobyns JH, Linscheid RL. Difficult wrist fractures. Perilunate fracture-dislocations of the wrist. Clin Orthop Relat Res 1987;(214):136-47.

11. Arwert HJ, Keizer S, Kromme CH, Vliet Vlieland TP, Meesters JJ. Validity of the Michigan hand outcomes questionnaire in patients with stroke. Arch Phys Med Rehabil 2016;97:238-44.
12. Graham JG, Penna S, Fletcher D, Kwok M, Aita DJ, Takei TR, et al. Outcomes of open reduction and internal fixation of bilateral fractures of the distal radius. J Hand Microsurg 2019;11:117-20.

13. Hevonkorpi TP, Launonen AP, Huttunen TT, Kannus P, Niemi S, Mattila VM. Incidence of distal radius fracture surgery in Finns aged 50 years or more between 1998 and 2016 - too many patients are yet operated on? BMC Musculoskelet Disord 2018;19:70.

14. Williksen JH, Frihagen F, Hellund JC, Kvernmo HD, Husby T. Volar locking plates versus external fixation and adjuvant pin fixation in unstable distal radius fractures: A randomized, controlled study. J Hand Surg Am 2013;38:1469-76.

15. Wang J, Lu Y, Cui Y, Wei X, Sun J. Is volar locking plate superior to external fixation for distal radius fractures? A comprehensive meta-analysis. Acta Orthop Traumatol Turc 2018;52:334-42.

16. Lee DY, Park YJ, Park JS. A Meta-analysis of studies of volar locking plate fixation of distal radius fractures: Conventional versus minimally invasive plate osteosynthesis. Clin Orthop Surg 2019;11:208-19.

17. Gouk C, Ng SK, Knight M, Bindra R, Thomas M. Long term outcomes of open reduction internal fixation versus external fixation of distal radius fractures: A meta-analysis. Orthop Rev (Pavia) 2019;11:7809.

18. Schmelzer-Schmied N, Wieloch P, Martini AK, Daecke W. Comparison of external fixation, locking and non-locking palmar plating for unstable distal radius fractures in the elderly. Int Orthop 2009;33:773-8.

19. Huang YY, Lin TY, Chen CH, Chou YC, Su CY. Surgical outcomes of elderly patients aged more than 80 years with distal radius fracture: Comparison of external fixation and locking plate. BMC Musculoskelet Disord 2020;21:91.

20. Mellstrand Navarro C, Ahrengart L, Törnqvist H, Ponzer S. Volar locking plate or external fixation with optional addition of K-wires for dorsally displaced distal radius fractures: A randomized controlled study. J Orthop Trauma 2016;30:217-24.

21. Egol K, Walsh M, Tejwani N, McLaurin T, Wynn C, Paksima N. Bridging external fixation and supplementary Kirschner-wire fixation versus volar locked plating for unstable fractures of the distal radius: A randomised, prospective trial. J Bone Joint Surg [Br] 2008;90:1214-21.

22. Landgren M, Jerrhag D, Tägil M, Kopylov P, Geijer M, Abramo A. External or internal fixation in the treatment of non-reducible distal radial fractures? Acta Orthop 2011;82:610-3.

23. Wright TW, Horodyski M, Smith DW. Functional outcome of unstable distal radius fractures: ORIF with a volar fixed-angle tine plate versus external fixation. J Hand Surg Am 2005;30:289-99.

24. Esposito J, Schemitsch EH, Saccone M, Sternheim A, Kuzyk PR. External fixation versus open reduction with plate fixation for distal radius fractures: A meta-analysis of randomised controlled trials. Injury 2013;44:409-16.

25. Margaliot Z, Haase SC, Kotsis SV, Kim HM, Chung KC. A meta-analysis of outcomes of external fixation versus plate osteosynthesis for unstable distal radius fractures. J Hand Surg Am 2005;30:1185-99.

26. Wu M, Li X, Li J, Chen Y. Operative vs conservative treatment in distal radius fractures: A protocol. Medicine (Baltimore) 2020;99:e21250.

27. He B, Tian X, Ji G, Han A. Comparison of outcomes between nonsurgical and surgical treatment of distal radius fracture: A systematic review update and meta-analysis. Arch Orthop Trauma Surg 2020;140:1143-53.

28. Ju JH, Jin GZ, Li GX, Hu HY, Hou RX. Comparison of treatment outcomes between nonsurgical and surgical treatment of distal radius fracture in elderly: A systematic review and metaanalysis. Langenbecks Arch Surg 2015;400:767-79. 